\title{
Effect of added struts and intake velocity on flame stabilization in supersonic combustors
}

\author{
Akram Mohammad \\ Department of Aerospace Engineering, King Abdulaziz University, Jeddah, Saudi Arabia \\ akramnmania@gmail.com,ammohamad4@kau.edu.sa
}

Submitted: 04/07/2018

Revised: 20/10/2020

Accepted: $27 / 10 / 2020$

\begin{abstract}
In the present computational study, the impact of strut positions and the effect of inlet Mach numbers on the combustion efficiency are investigated in a strut-based supersonic combustor. An experimentally investigated model combustor developed at the German Aerospace Center (DLR) is simulated and validated. Then, a model combustor with three struts placed at different positions is investigated. Two-dimensional, compressible, reacting-flow governing equations are solved along with single-step chemistry reaction and k- $\omega$ SST turbulence model using a commercial CFD code FLUENT. The oblique shock from the struts has a profound influence on the mixing and combustion process. The $\mathrm{H}_{2} \mathrm{O}$ mole fraction, $\mathrm{H}_{2}$ mole fraction contours, and combustion efficiency of various configurations are compared for finding better mixing and flame stabilization. The combustion efficiency reduces when the two struts are located in farther downstream or placed at the same downstream location. At higher Mach numbers, the combustion is delayed, and the mixing of fuel with the supersonic mainstream is incomplete.
\end{abstract}

Keywords: Supersonic combustion; Scramjets; Struts; Hydrogen.

\section{INTRODUCTION}

High-speed combustion research is of paramount importance towards the development of high-speed vehicles. The flam stabilization studies are of paramount importance in these high-speed engines (Segal, 2009; W. Huang et al., 2010; Z. Huang et al., 2015; W. Huang et al., 2011; Karagozian, 2010; Qin et al., 2017). The liquid fuel must be injected (atomized), evaporated, mixed with air, react, and burned completely within a very short span of resident time. The combustor inlet Mach number is in the range of 2-3 for scramjets flying in the range of Mach 6-8 (Segal, 2009). This essentially explains why it is imperative to address the impact of inlet Mach number on the fuel-air mixing and flame stabilization.

At high combustor inlet Mach numbers, the level of fuel-air mixing that can be attained through the diffusive and convective processes is limited; as a result, the overall combustion efficiency and thrust decrease. Because of these inherent difficulties, there is a need for the development of flame holding schemes that improve fuel-oxidizer mixing. Different injection schemes, including the position, the shape of the injectors, and arrangement of injection have been scrutinized in order to improve mixing (Ben-Yakar and Hanson, 1998; Lee et al., 2013; Hu et al., 2014; Zhang et al., 2017; Zhao, Liang, and Zhao, 2016), flame stabilization and flame holding. Circular, rectangular, and elliptical injection geometries (Gruber et al., 2000; Rust, Gerlinger, and Aigner, 2010) are proposed for flame stabilization in supersonic combustors. Also, various fuel injection strategies such as transverse injection (Gruber et al., 2000; Choi, Ma, and Yang, 2005; W. Huang, Yang, and Yan, 2013), parallel injection (Kumar, Das, and Sheelam, 2014; Hariharan, 
Velamati, and Prathap, 2016), and angled injection (Jeong et al., 2008) of fuel were incorporated. A strong bow shock wave is produced due to the transverse injection of fuel. Upstream of the injection point boundary layer separates due to interaction with a shock wave. This leads to higher stagnation pressure losses due to strong bow shock. However, it is possible to lessen total pressure losses by performing angled or parallel injection. Due to their restricted mixing capabilities, improved schemes for mixing enhancement are essential. This is done by shock waves (Shekarian, Tabejamaat, and Shoraka, 2014; Mudford et al., 2003) or by the formation of stream-wise vortices (Gerlinger et al., 2008; Hsu et al., 2009). Shekarian et al. (Shekarian, Tabejamaat, and Shoraka, 2014) analysed the effects of the incident oblique shock wave, and the normal fuel injection on the fuel/air mixing and combustion computationally. The study was carried out for an inlet stagnation pressure $0.5 \mathrm{MPa}$, Mach 2.5, with and without oblique shock presence. The oblique shock augmented the recirculation zone length and increased the mixing of hydrogen fuel and air significantly. Flame anchoring and flame stabilization in a supersonic combustor have been accomplished using enhancement methods like struts (Rust, Gerlinger, and Aigner, 2010; Kumar, Das, and Sheelam, 2014; Ground et al., 2014; Bao et al., 2013), backward-facing step (Kumaran and Babu, 2009a), Diamond strut (Deepu, Gokhale, and Jayaraj, 2007), ramp (Hönig et al., 1996), pylon (Vergine et al., 2012), cavity (Ben-Yakar and Hanson, 1998; Lee et al., 2013; Choi, Ma, and Yang, 2005; Baurle and Gruber, 1998; Grady et al., 2012), and combinations of these (Kumaran and Babu, 2009a; Grady et al., 2012). From the abovementioned practices, the strut-based parallel fuel injectors are preferred in most of the supersonic combustors, as the overall pressure loss associated with them is the least when compared to the normal injection. The strut-based injection not only injects fuel into mainstream air-flow, but also performs uniform dispersion of the hydrogen fuel in the lateral (transverse) direction. The base of the strut forms a wake region that anchors the flame at a location.

Several researchers employed strut injectors with various geometries in supersonic combustors. An staged supersonic combustor is investigated experimentally by Tomioka et al. (2001). The combustor was tested for inlet Mach number of 2.5 and a stagnation temperature of $1500 \mathrm{~K}$. The strut is used for the primary injection, and wall injectors in the diverging section deliver the secondary injection. The second-stage injection resulted in higher thrust and lower combustion efficiency. A three-dimensional numerical analysis with a strut injector is conducted by Kumaran and Babu (2009a). Different schemes of injections, such as strut, wall, and strut and wall (i.e., staged), are investigated in their work. They suggested that the $k-\omega$ SST model predicts the mixing better compared to the Spalart-Allmaras single equation turbulence model. They also investigated (Kumaran and Babu, 2009b) the role of single and detailed reaction chemistry models. The reaction flow pattern predictions were better with a detailed chemistry model. However, to reduce the computational cost of single-step reaction models, it can be used.

Pulsed laser induced fluorescence (PLIF) technique is utilized by Hsu et al. (2009) to gain insight into the mechanism of fuel and air mixing at two different Mach numbers. The strut geometry such as shape, angle, and the length was found to have a significant influence on the mixing. For better mixing conditions, a strut with a greater wedge angle and smaller root length is proposed. A detailed numerical analysis of hydrogen-air turbulent combustion in a DLR combustor using a two-equation $k-\varepsilon$ model along with a laminar stretched flamelet model is performed by Oevermann (2000). Fuel (hydrogen) was injected from the base of the strut to the mainstream at the sonic condition. The static temperature of air and hydrogen was $340 \mathrm{~K}$ and $250 \mathrm{~K}$, respectively, numerically simulating the DLR combustor using a $k$ - $\omega$ turbulence model combined with a flamelet model for the reactions (Jianwen and Jialing, n.d.). It was concluded that the interaction between turbulence and combustion is imperative. The turbulent combustions in a DLR scramjet engine is simulated by Zou, Zheng, and Liu (2007) using a Partially Resolved Numerical Simulation (PRNS) procedure. The study provided an accurate description of turbulence in the scramjet engine with PRNS. Both reacting and non-reacting flows were simulated. The optimization studies in a strut-based supersonic DLR combustor are reported by Kumar, Das, and Sheelam (2014). The laminar finite model with the single-step chemistry model has been used for reacting flow simulations. The parametric analysis of the DLR combustor using the $k-\omega$ SST model with a finite rate/eddy dissipation model was carried out by W. Huang et al. (2011). They showed that, with an increase in injection temperature and pressure, the waves get pushed out of the combustor, and the flow becomes subsonic after a normal shock. However, the effects of Mach number and the impact of strut positions in a combustion flow field are rarely investigated. 
Even though there is an array of important parameters, which influence the flame stabilization and combustion efficiency, we restrict the objective of the present work to investigate the effect of strut positions at various inlet Mach numbers for a supersonic combustor with strut-based flame holders. The base model combustor geometry in the present study is adapted from Oevermann (2000). The flow phenomenon for various strut configurations is described in the present work. The combustion and mixing efficiency are also studied for each of the configurations. The Mach number at the combustor inlet is varied from 2.0 to 3.0 to study the operating range of the combustor.

\section{COMPUTATIONAL METHODOLOGY Reference DLR Geometry}

A scramjet combustor developed at the DLR is used for validation of the CFD code. The geometry is illustrated in Figure 1. The air enters through the combustor inlet, and hydrogen is injected parallel to the airstream at the base of the strut through a hole of $1 \mathrm{~mm}$ diameter as shown in Figure 1.

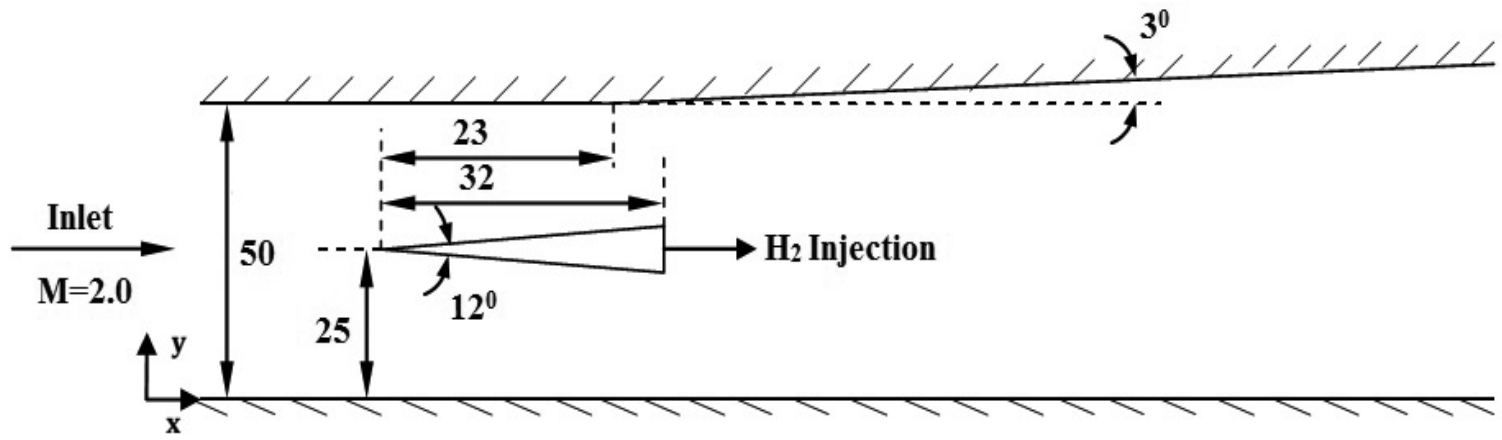

Figure 1. Schematic of DLR combustor geometry. All the dimensions are in $\mathrm{mm}$.

\section{PROPOSED COMBUSTOR DOMAIN}

The two-dimensional model combustor with detailed dimensions proposed in the present work is illustrated in Figure 2. Hydrogen $\left(\mathrm{LH}_{2}\right)$ is injected via the base of the strut. This strut serves the purpose of flame holding inside the combustor. The area of the combustor remains the same until $80 \mathrm{~mm}$ from the inlet of the combustor. The constant area section is followed by a diverging channel with a divergence angle of $3^{0}$ for both the upper and lower walls of the combustor. The complete length of the computational domain is taken as $700 \mathrm{~mm}$.

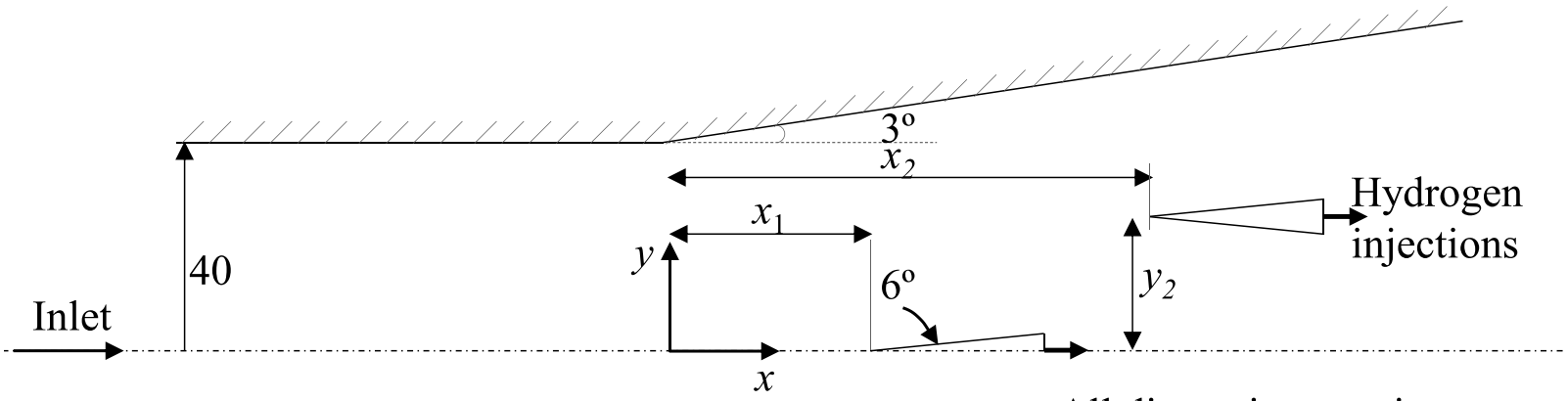

All dimensions are in $\mathrm{mm}$.

Figure 2. Schematic of the proposed strut-based scramjet combustors. 


\begin{tabular}{|c|c|c|c|c|}
\hline \multicolumn{5}{|c|}{ Table 1. Design points inside the combustor. } \\
\hline Case & $\boldsymbol{x}_{\boldsymbol{1}}$ & $\boldsymbol{y}_{\boldsymbol{1}}$ & $\boldsymbol{x}_{\boldsymbol{2}}$ & $\boldsymbol{y}_{\boldsymbol{2}}$ \\
\hline DLR & -23.0 & 0.0 & - & - \\
\hline 1 & 32.0 & 0.0 & 182 & 20.0 \\
\hline 2 & 357.5 & 0.0 & 42.5 & 30.0 \\
\hline 3 & 200.0 & 0.0 & 42.5 & 30.0 \\
\hline 4 & 357.5 & 0.0 & 357.5 & 30.0 \\
\hline 5 & 170.0 & 0.0 & 545.0 & 45.0 \\
\hline 6 & 545.0 & 0.0 & 170.0 & 15.0 \\
\hline
\end{tabular}

The struts are positioned at different locations by changing the positions of one primary central strut and two secondary struts. The origin of the axes is the starting off wall divergence on the symmetry line. The apex of the first strut is located at coordinates $x_{1}$ and $y_{1}$ as shown in Figure 2. The second strut is placed with $x_{2}$ and $y_{2}$ being coordinates of strut apex. The design points obtained are listed in Table 1. Various other combinations were selected; they are not presented here to avoid ambiguities.

\section{COMPUTATIONAL GRID}

The symmetric two-dimensional structured computational grid was prepared using GAMBIT. The grid was refined near computationally important areas such as fuel injectors and strut surfaces. This helps in capturing the shock waves neatly. On the other hand, a coarse mesh was deployed at the inlet and exit sections of the combustor.

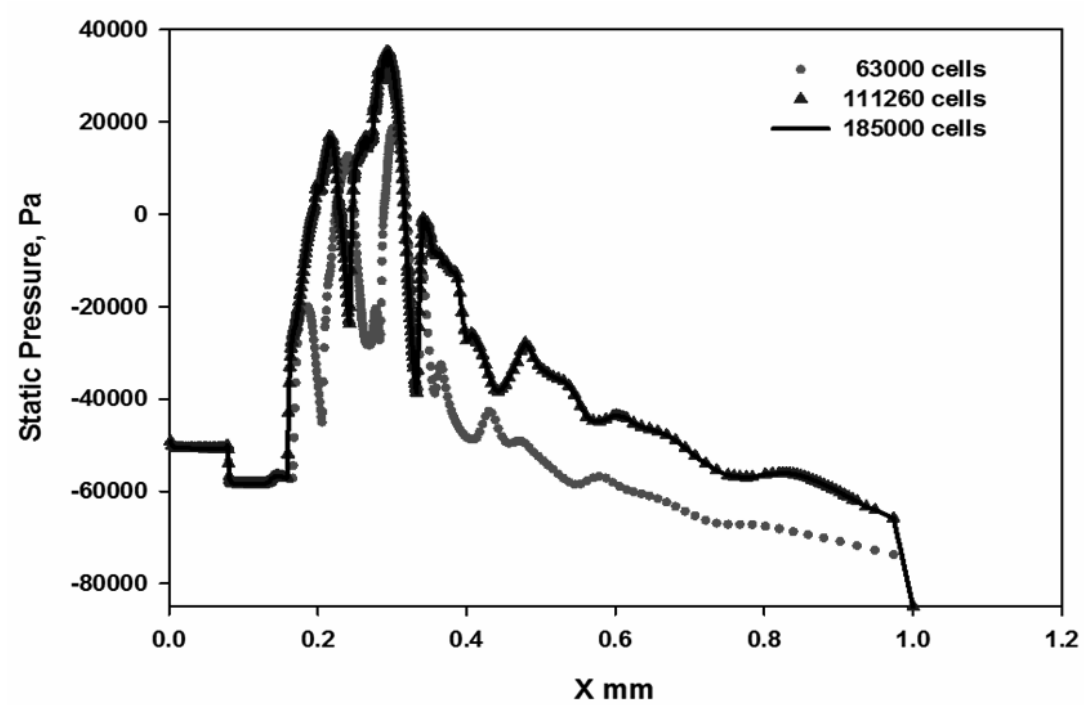

Figure 3. Static pressure distribution along the axis for three different mesh densities.

For an initial solution, 63000 cells were considered. The grid was then refined to 111260 cells based on the static pressure gradient. A further adaptation based on the fuel mass fraction gradient resulted in 185000 cells. A significant difference can be observed for coarse and fine mesh densities. However, static pressure distributions at the upper wall with these two mesh densities (111260 and 185000) were found to be similar as can be seen from Figure 3 . This suggests that the mesh refinement with the gradient of fuel mass fraction with 185000 cells is accurate enough to make 
the solution grid-independent and capture the essential features of flow fields and flame. The static temperature also confirms grid-independent results for the mesh density with 185000 cells.

\section{BOUNDARY CONDITIONS}

At the combustor inlet static pressure, total pressure, total temperature, and mole fractions of fuel and oxidizer were specified. At the domain outlet, the pressure-outlet boundary condition was specified. Zero heat flux and nonslip boundary conditions were imposed on the strut and combustor walls. The air at the combustor inlet has a static pressure and a static temperature of $0.1 \mathrm{MPa}$ and $340 \mathrm{~K}$, respectively. Hydrogen was injected at sonic conditions for all the configurations. The static pressure and stagnation temperature for the fuel inlet were $1.21 \mathrm{bar}$ and $464 \mathrm{~K}$. The inlet Mach number upstream of the combustor was changed with an increment of 0.5 from Mach 2.0 to 3.0. Table 2 gives numerical values specified at the domain boundaries of DLR geometry.

For the proposed models, the inlet Mach number is varied considering the same inlet static parameters and type of boundary conditions.

Table 2. Boundary conditions for combustor inlet and fuel injection for DLR geometry.

\begin{tabular}{|l|l|l|}
\hline Parameters & Air & Hydrogen \\
\hline Mach Number & $2.0,2.5,3.0$ & 1.0 \\
\hline Static Temperature (Kelvin, K) & $340 \mathrm{~K}$ & $250 \mathrm{~K}$ \\
\hline Static Pressure (Pascal, Pa) & $1 \times 10^{5} \mathrm{~Pa}$ & $1 \times 10^{5} \mathrm{~Pa}$ \\
\hline Mole fraction of $\mathrm{O}_{2}$ & 0.232 & 0 \\
\hline Mole fraction of $\mathrm{N}_{2}$ & 0.736 & 0 \\
\hline Mole fraction of $\mathrm{H}_{2} \mathrm{O}$ & 0.032 & 0 \\
\hline Mole fraction of $\mathrm{H}_{2}$ & 0 & 1 \\
\hline
\end{tabular}

\section{GOVERNING EQUATIONS}

The mass, momentum, energy, and species conservation equations are resolved and solved in two-dimensional coordinates. Compressibility effects are considered using the ideal gas law. A two-equation $k-\omega$ SST turbulence model using time-averaged Reynolds averaged quantities is employed as suggested by Kumaran and Babu (Kumaran and Babu, 2009a). Single-step reaction kinetics has been used. Thermal as well as multicomponent diffusion models are used. Computations are carried out using the commercial solver Fluent (“ANSYS Fluent - CFD Software,” n.d.).

\section{RESULTS AND DISCUSSION REFERENCE DLR GEOMETRY ANALYSIS}

The static pressure contours for the nonreacting case are shown in Figure 4. Oblique shock is generated from the strut. The boundary layer on the strut walls separates due to the negative pressure gradient existence. The oblique shock reflects from the top and bottom walls and propagates downstream. A low subsonic velocity recirculation zone is found downstream of the base of the strut. Fuel is introduced into the subsonic recirculation zone, which acts as a flame anchor. The flow accelerates from subsonic to the supersonic regime in the wake region.

The flow phenomenon significantly changes when the combustion is initiated. The recirculation zone behind the strut enlarges due to combustion. This is mainly because the oblique shock generated from the strut falls to the wake region. The recirculation of flow increases the residence time of the fuel-air mixture within the combustor, which helps in anchoring/holding the flame. A rise in the temperature is noted, and this initiates the autoignition of hydrogen from 
the base of the strut. This phenomenon is well illustrated in static temperature contour. The temperature in this region is about $2500 \mathrm{~K}$. High static pressures are observed for the reacting flow case, which is attributable to heat addition due to combustion.

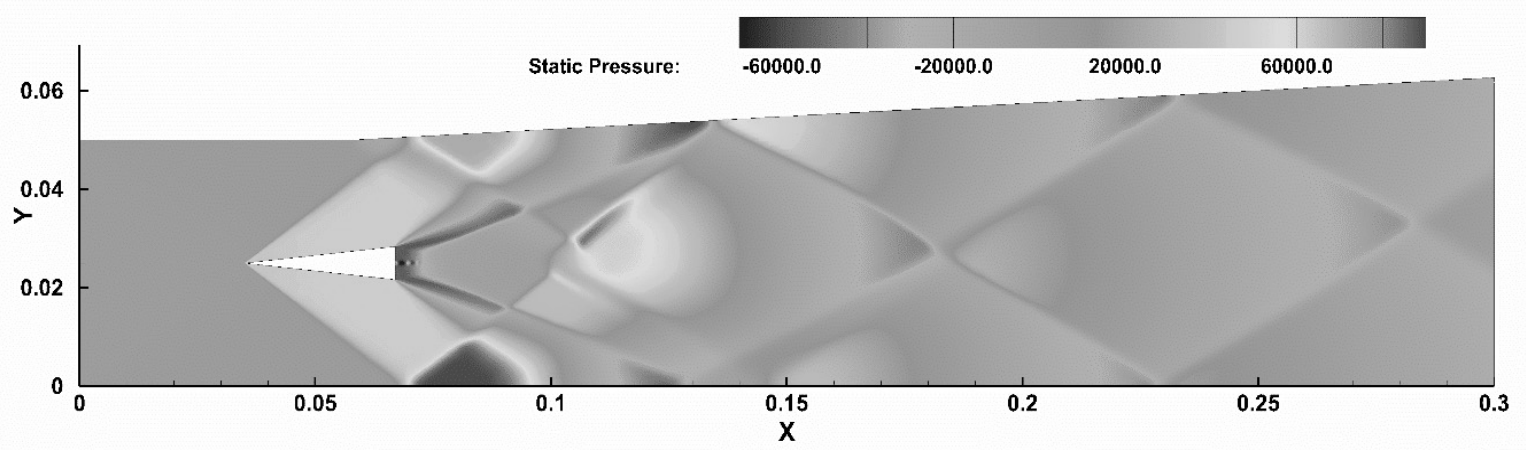

Figure 4. Static pressure contours for the mixing case inside reference DLR geometry.

The predicted results for mixing and reacting flow are compared with the experimental results obtained by Oevermann (Oevermann, 2000) as shown in Figure 5(a) and 5(b). For the mixing case, the static pressure on the lower wall is compared with that of the experiment. The static temperature at $X=78 \mathrm{~mm}$ from the inlet is compared to that of the reacting case. The study is also carried out for S-A and $k-\omega$ SST turbulence models. The investigation shows that the predictions by the $k-\omega \mathrm{SST}$ model are much closer to the experimental results.

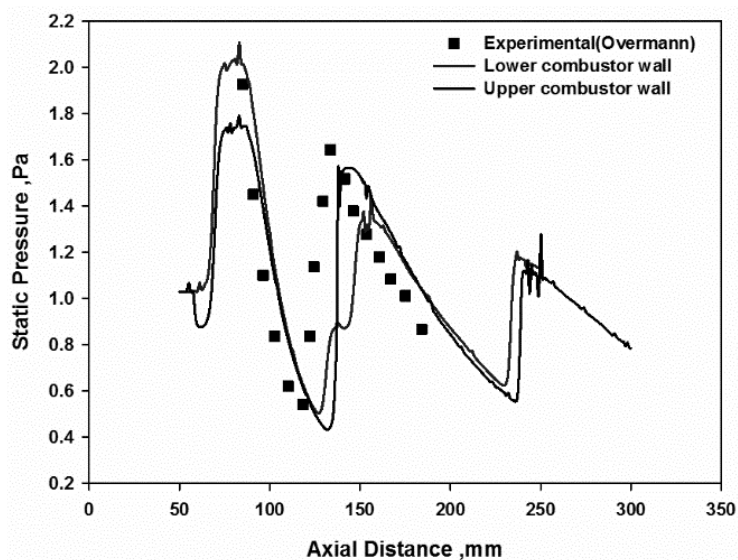

Figure 5. (a) Static pressure comparison and mixing case with the experimental studies inside reference DLR geometry (Oevermann 2000).

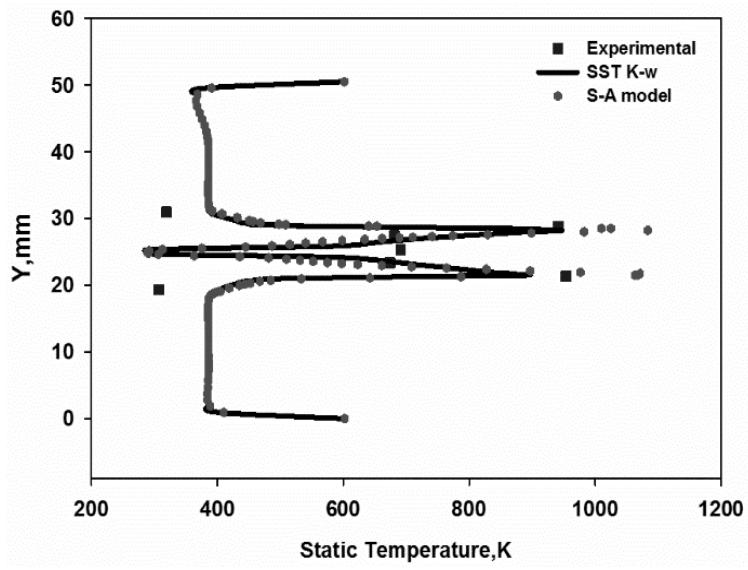

(b) static temperature comparison for reacting flow with the experimental studies inside reference DLR geometry (Oevermann, 2000)

\section{PROPOSED GEOMETRY ANALYSIS}

After validation with reference DLR geometry, computations were performed to study the effects of strut positions and the effect of Mach number with the proposed six configurations given in Table 1. The specifications are as explained in section 2.2. Initially, the effect of strut positions is investigated at inlet Mach number 2.0. The effect of the Mach number is also investigated by running the combustor at Mach 2.5 and 3.0. The combustion efficiency in the present analysis is estimated using 


$$
\eta_{\text {comb }}=\left(\frac{T_{O, e x i t}-T_{o, \text { inlet }}}{T_{O, \text { max }}-T_{O, \text { inlet }}}\right) \times 100
$$

where the stagnation temperature at the combustor exit is $T_{O, \text { exit }}, T_{O, \text { inlet }}$ is the stagnation temperature at the combustor inlet, and $T_{O, \max }$ is the maximum stagnation temperature inside the combustor. $T_{O, \text { exit }}, T_{O, \text { inlet }}$ are calculated by taking a mass-weighted average at the exit and inlet on the combustor. $T_{O, \max }$ is computed by taking the maximum function in the entire computational domain.

Figure 6 shows the Mach number, the mole fraction of $\mathrm{H}_{2}, \mathrm{H}_{2} \mathrm{O}$, and static temperature contours for the reacting flow. The oblique shocks occur from the tip of the strut. Due to multiple reflections of the shock, the thickness of the boundary layer increases. Static pressure rises across the oblique shock and in the region of combustion. A large subsonic region is noted for the base case, which enhances fuel residence time. The fuel is injected into this recirculation region, and mixing is enhanced. A static temperature rise to $2400 \mathrm{~K}$ is observed.

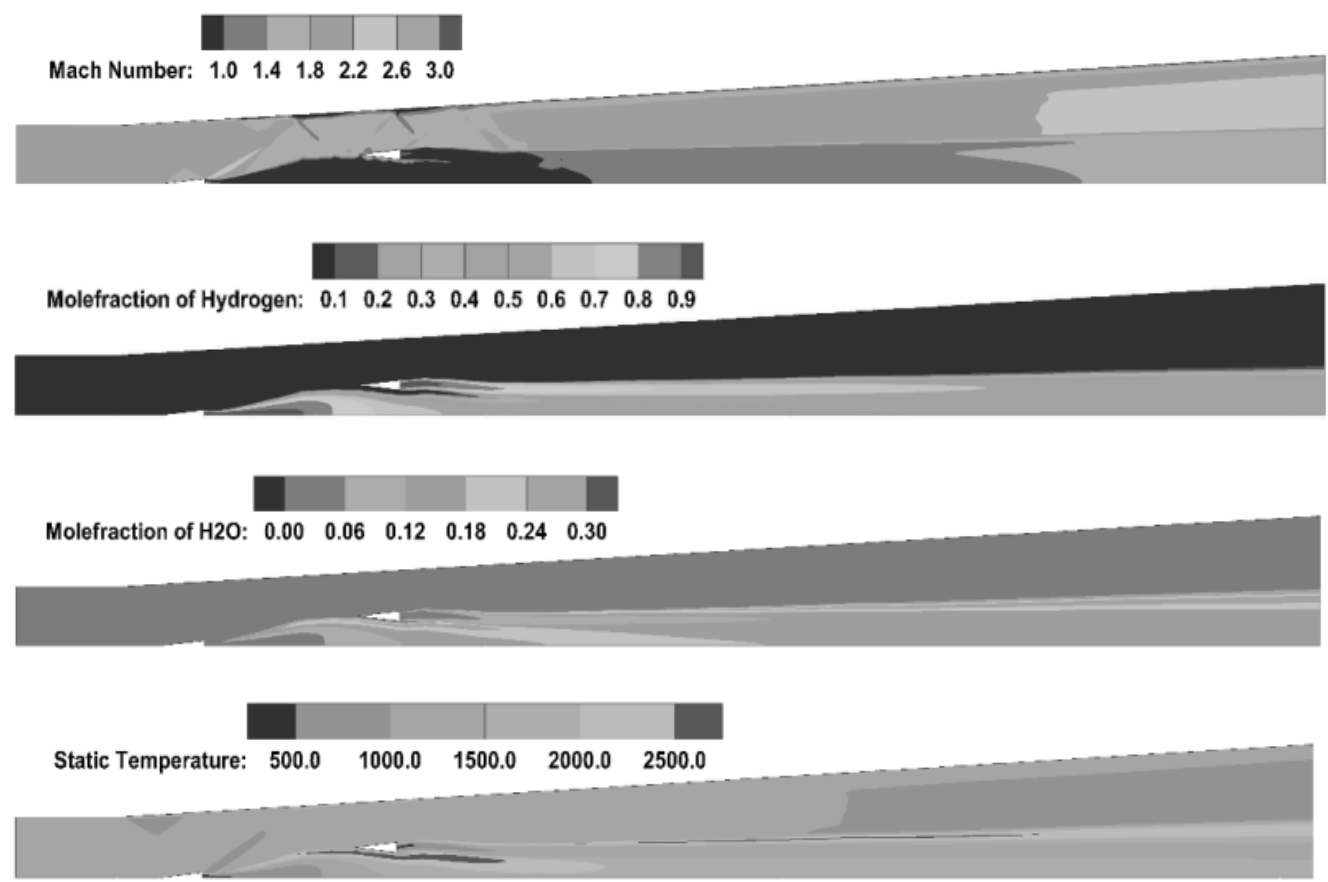

Figure 6. Contours of Mach number, $\mathrm{H}_{2}$ mole fraction, $\mathrm{H}_{2} \mathrm{O}$ mole fraction, and static temperature for the base case 1 (with coordinates $\mathrm{x}_{1} 32.0, \mathrm{y}_{1} 0.0 ; \mathrm{x}_{2} 182.0 ; \mathrm{y}_{2} 20.0$ ).

\section{EFFECT OF STRUTS POSITION}

All the strut configurations listed in Table 1 are simulated for an inlet Mach number of 2.0 with a stagnation temperature of $1700 \mathrm{~K}$ and stagnation pressure of 3.91 bars as mentioned before. An attached oblique shock is generated from the struts to the mainstream supersonic flow. The resulting shock reflects from both the bottom and top walls of the combustor. The Mach number contours for a few strut configurations are shown in Figure 7. The Mach number contours in Figure 7 show a large subsonic recirculation region formed at the base of the strut. The formation of the subsonic recirculation region is noted for all the combustor strut configurations. The extended recirculation zone holds the flame in a better fashion. The velocity near the mixing layer attenuates from subsonic to supersonic speeds further downstream in the combustor. 


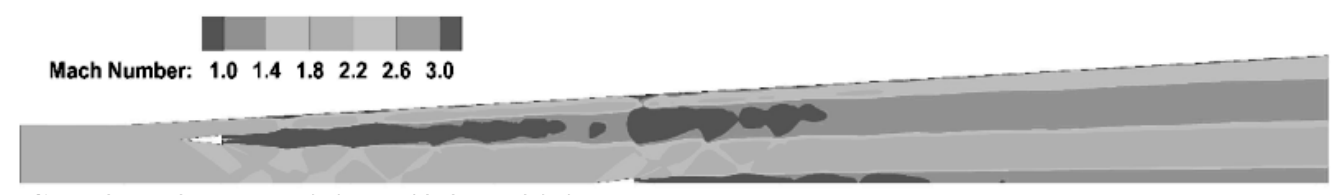

Case $2: \mathrm{x}_{1} 357.5, \mathrm{y}_{1} 0.0 ; \mathrm{x}_{2} 42.2 ; \mathrm{y}_{2} 30.0$

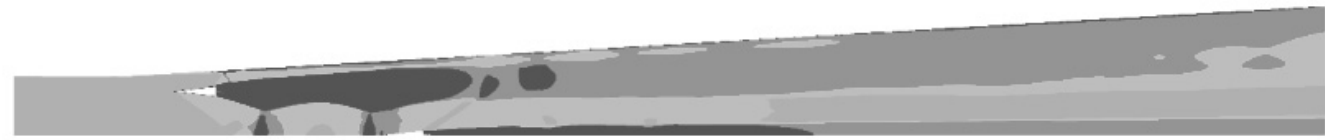

Case 3: $\mathrm{x}_{1} 200.0, \mathrm{y}_{1} 0.0 ; \mathrm{x}_{2} 42.2 ; \mathrm{y}_{2} 30.0$

Case $4: \mathrm{x}_{1} 357.5, \mathrm{y}_{1} 0.0 ; \mathrm{x}_{2} 357.5 ; \mathrm{y}_{2} 30.0$

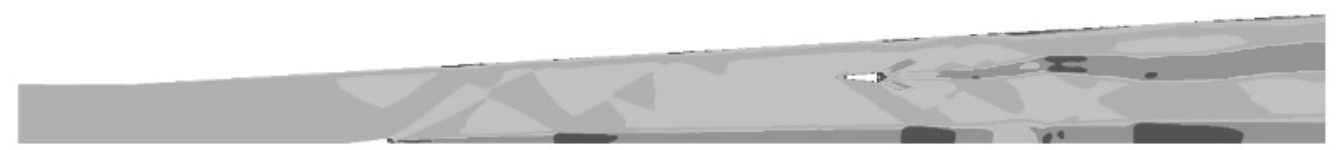

Case 5: $\mathrm{x}_{1} 170.0, \mathrm{y}_{1} 0.0 ; \mathrm{x}_{2} 545.0 ; \mathrm{y}_{2} 45.0$

Figure 7. Mach number contours for various strut configurations of Case 2 (with coordinates $\mathrm{x}_{1} 357.5, \mathrm{y}_{1} 0.0 ; \mathrm{x}_{2}$ 42.2; $\mathrm{y}_{2} 30.0$ ), Case 3 (with coordinates $\mathrm{x}_{1} 200.0, \mathrm{y}_{1} 0.0 ; \mathrm{x}_{2} 42.2 ; \mathrm{y}_{2} 30.0$ ), Case 4 (with coordinates $\mathrm{x}_{1} 357.5, \mathrm{y}_{1} 0.0$; $\mathrm{x}_{2} 357.5 ; \mathrm{y}_{2} 30.0$ ), and Case 5 (with coordinates $\mathrm{x}_{1} 170.0, \mathrm{y}_{1} 0.0 ; \mathrm{x}_{2} 545.0 ; \mathrm{y}_{2} 45.0$ ), respectively.

The boundary layer at the strut walls splits due to the existence of a negative pressure gradient owing to the presence of an oblique shock at the sharp tip of the wedge. This separation of the boundary layer over the strut develops a mixing layer between the wake and the supersonic main flow, which develops almost throughout the downstream of the strut. The oblique and reflected shocks increase static pressure.

Two secondary struts are placed upstream (cases 2 and 3), overlap (case 4), and downstream (case 5) of the central primary strut. The Mach number contours in cases 2 and 3 show a large subsonic recirculation region in the base of the strut. The placement of the struts farther downstream reduces the width of the recirculation zone. In Figure 7 for Case 3, two low Mach number bubbles are appearing upstream of the central injector. This could be related to thermal choking. 


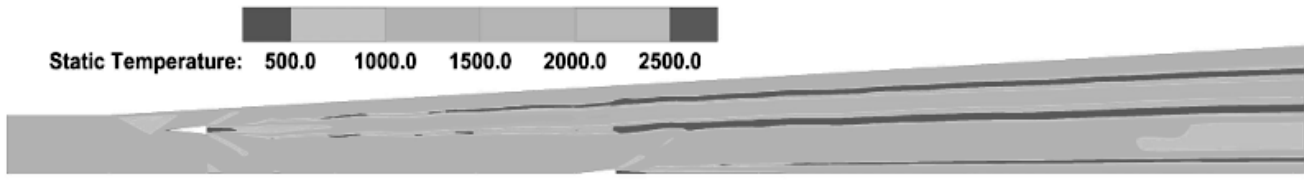

Case $2: \mathrm{x}_{1} 357.5, \mathrm{y}_{1} 0.0 ; \mathrm{x}_{2} 42.2 ; \mathrm{y}_{2} 30.0$

Case 3: $\mathrm{x}_{1} 200.0, \mathrm{y}_{1} 0.0 ; \mathrm{x}_{2} 42.2 ; \mathrm{y}_{2} 30.0$

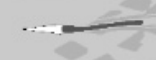

Case $4: \mathrm{x}_{1} 357.5, \mathrm{y}_{1} 0.0 ; \mathrm{x}_{2} 357.5 ; \mathrm{y}_{2} 30.0$

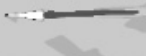

Case 5: $\mathrm{x}_{1} 170.0, \mathrm{y}_{1} 0.0 ; \mathrm{x}_{2} 545.0 ; \mathrm{y}_{2} 45.0$

Figure 8. Static temperature contours for various strut configurations of Case 2 (with coordinates $\mathrm{x}_{1} 357.5, \mathrm{y}_{1} 0.0 ; \mathrm{x}_{2}$ $42.2 ; \mathrm{y}_{2} 30.0$ ), Case 3 (with coordinates $\mathrm{x}_{1} 200.0, \mathrm{y}_{1} 0.0 ; \mathrm{x}_{2} 42.2 ; \mathrm{y}_{2} 30.0$ ), Case 4 (with coordinates $\mathrm{x}_{1} 357.5, \mathrm{y}_{1} 0.0$; $\mathrm{x}_{2} 357.5 ; \mathrm{y}_{2} 30.0$ ), and Case 5 (with coordinates $\mathrm{x}_{1} 170.0, \mathrm{y}_{1} 0.0 ; \mathrm{x}_{2} 545.0 ; \mathrm{y}_{2} 45.0$ ), respectively.

Figure 8 shows the contours of static temperature for few strut configurations. The reflected shocks from the top wall of the combustor impinge on the shear layer developed at the base of the strut. The local impingement of these shocks causes the static temperature to rise to $2440 \mathrm{~K}$. This enhances flame-holding and combustion phenomenon. The shock waves reflected from the combustor bottom and top walls significantly influence the boundary layers at various locations, thereby initiating the boundary layers to coagulate and also enhancing the wall temperatures.

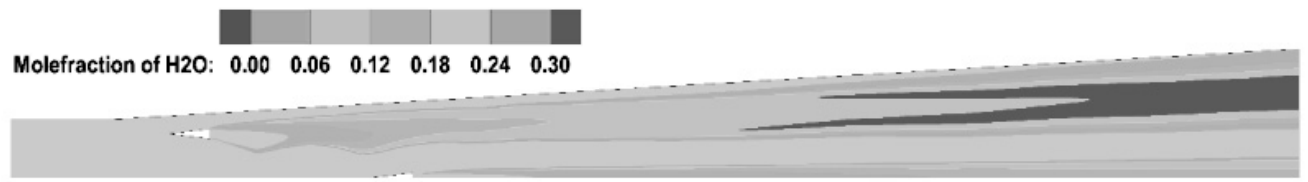

Case 3: $\mathrm{x}_{1} 200.0, \mathrm{y}_{1} 0.0 ; \mathrm{x}_{2} 42.2 ; \mathrm{y}_{2} 30.0$

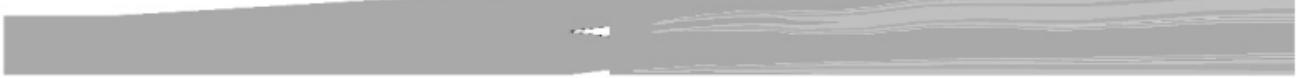

Case $4: \mathrm{x}_{1} 357.5, \mathrm{y}_{1} 0.0 ; \mathrm{x}_{2} 357.5 ; \mathrm{y}_{2} 30.0$

Case $5: \mathrm{x}_{1} 170.0, \mathrm{y}_{1} 0.0 ; \mathrm{x}_{2} 545.0 ; \mathrm{y}_{2} 45.0$

Figure 9. Contours of mole fraction of $\mathrm{H}_{2} \mathrm{O}$ for various strut configurations of Case 3 (with coordinates $\mathrm{x}_{1} 200.0, \mathrm{y}_{1}$ $0.0 ; \mathrm{x}_{2} 42.2 ; \mathrm{y}_{2} 30.0$ ), Case 4 (with coordinates $\mathrm{x}_{1} 357.5, \mathrm{y}_{1} 0.0 ; \mathrm{x}_{2} 357.5 ; \mathrm{y}_{2} 30.0$ ), and Case 5 (with coordinates $\mathrm{x}_{1}$ $\left.170.0, \mathrm{y}_{1} 0.0 ; \mathrm{x}_{2} 545.0 ; \mathrm{y}_{2} 45.0\right)$, respectively. 
Figure 9 illustrates the $\mathrm{H}_{2} \mathrm{O}$ mole fraction contours. The formation of $\mathrm{H}_{2} \mathrm{O}$ shows the presence of a flame. The contour clearly shows the penetration of fuel jet, diffusion, and mixing of fuel and air mixture due to the influence of the oblique shock. The total temperature at the exit is maximum for the Case 3 (with coordinates $\mathrm{x}_{1} 200.0, \mathrm{y}_{1} 0.0$; $\left.\mathrm{x}_{2} 42.2 ; \mathrm{y}_{2} 30.0\right)$ as the interaction of the reflections is much more compared with that of other cases. The shear layer of the strut gets strongly influenced by these oblique shocks. The change of $\boldsymbol{y}_{2}$ coordinate from $30 \mathrm{~mm}$ to $45 \mathrm{~mm}$ has little influence on combustion efficiency. From the numerical study, the combustion efficiency is maximum for Case 3 (with coordinates $\mathrm{x}_{1} 200.0, \mathrm{y}_{1} 0.0 ; \mathrm{x}_{2} 42.2 ; \mathrm{y}_{2} 30.0$ ). The efficiency of this strut configuration is $64.5 \%$. The combustor efficiency for Case 4 (with coordinates $\mathrm{x}_{1} 357.5, \mathrm{y}_{1} 0.0 ; \mathrm{x}_{2} 357.5 ; \mathrm{y}_{2} 30.0$ ) is $42.31 \%$. The strut configurations with two sets of fore and aft struts show higher efficiency compared to those of other cases. The mole fraction goes as high as 0.30 for these cases as the flow reaches the exit of the combustor.

\section{EFFECT OF MACH NUMBER}

This section discusses the effect of variation of inlet Mach number on the mixing and flame stabilization. The inlet Mach number is increased by 0.5 from Mach 2.0 to Mach 3.0. The contours of Mach number, $\mathrm{H}_{2}$ mole fraction, $\mathrm{H}_{2} \mathrm{O}$ mole fraction, and static temperature are illustrated in Figures 10-13.

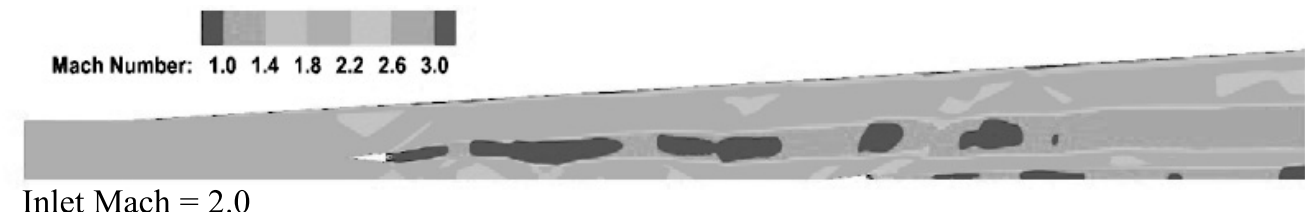

Inlet Mach $=2.0$

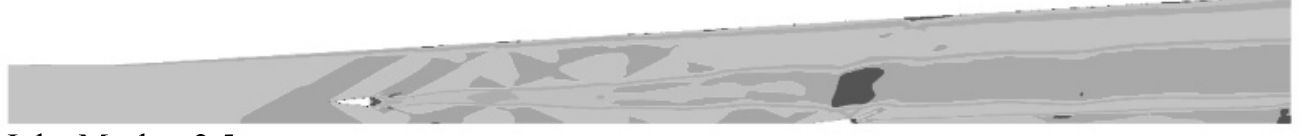

Inlet Mach $=2.5$

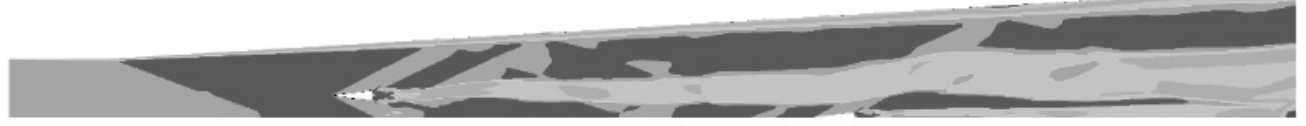

Inlet Mach $=3.0$

Figure 10. Contours of Mach number for the configuration of Case 6 (with coordinates $x_{1} 545.0, y_{1} 0.0$;

$$
\left.\mathrm{x}_{2} 170.0 ; \mathrm{y}_{2} 15.0\right) \text {. }
$$

The distance of the oblique shock incidence at the top wall of the combustor increases with an increase in the Mach number. This is because of the shock wave angle, and $\beta$ decreases with increase in the Mach number when the strut angle is kept constant. The contours illustrated in Figure 10 show the reflections of the oblique shock from the top and bottom wall of the combustor. The multiple reflections from combustor walls have a great impact on mixing and enhancing the combustion phenomenon of the combustor as explained in the earlier section. Static pressure at the inlet decreases with an increase in the inlet Mach number. An instantaneous increase in static pressure is observed across the oblique shock as expected. All the strut configurations show a similar flow phenomenon.

The contours of hydrogen (fuel) mole fraction shown in Figure 11 represent the penetration of the fuel into the supersonic flow stream for a range of inlet Mach numbers 2-3. The diffusion of the hydrogen is rapid for the inlet Mach 2.0. As the Mach number is increased to 2.5 and 3.0, the diffusion of the hydrogen to the mainstream happens in a much slower rate. The inlet flow velocity magnitude for inlet Mach 3.0 is in the order $1550 \mathrm{~m} / \mathrm{s}$. The base of the strut with recirculation zone acts as a flame holder. The oblique shocks reflected have no much influence for high Mach flows. 

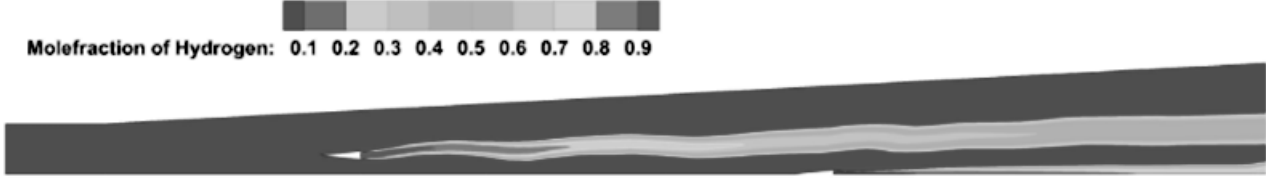

Inlet Mach $=2.0$

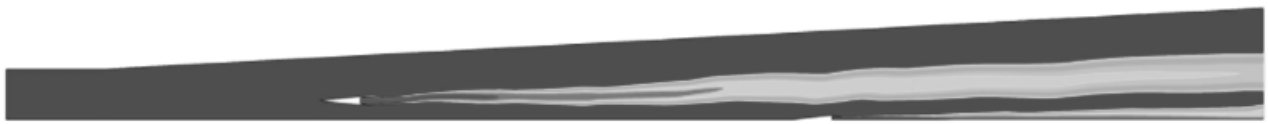

Inlet Mach $=2.5$

$\underline{-1}$

Inlet Mach $=3.0$

Figure 11. Contours of hydrogen (fuel) for the configuration of Case 6 (with coordinates $x_{1} 545.0, y_{1} 0.0$;

$$
\left.\mathrm{x}_{2} 170.0 ; \mathrm{y}_{2} 15.0\right) \text {. }
$$

The diffusion of the hydrogen is rapid for inlet Mach 2.0. As the Mach number at the inlet increases to 3.0, the mixing of the hydrogen into the mainstream happens at a much slower rate. The velocity magnitude for inlet Mach 3.0 is in the order $1550 \mathrm{~m} / \mathrm{s}$. The oblique shocks reflected no influence for high Mach flows.

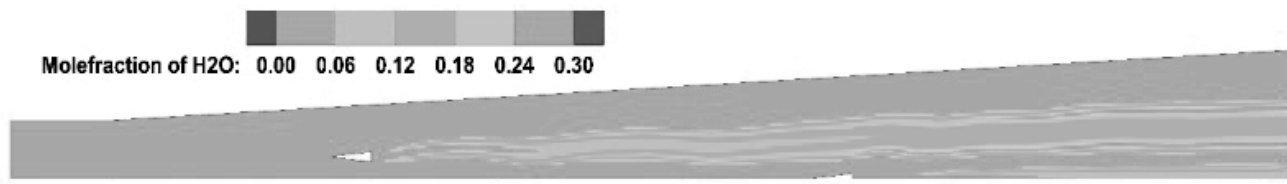

Inlet Mach $=2.0$

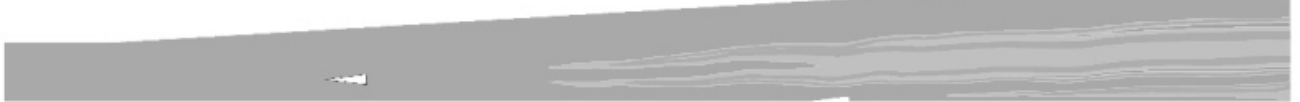

Inlet Mach $=2.5$

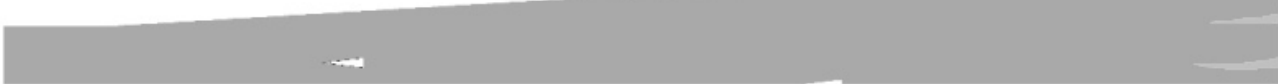

Inlet Mach $=3.0$

Figure 12. Contours of $\mathrm{H}_{2} \mathrm{O}$ for the configuration of Case 6 (with coordinates $\mathrm{x}_{1} 545.0, \mathrm{y}_{1} 0.0 ; \mathrm{x}_{2} 170.0 ; \mathrm{y}_{2}$ 15.0).

For Mach 2.0, as in Figure 10, subsonic regions are formed when the reflections from the bottom wall of the combustor meet the flow from the base of the strut. These subsonic regions help in improving the static temperature to rise and enhance the combustion phenomenon. Since there is no heat addition in shock phenomenon, the total enthalpy and total temperature remain constant across the shocks. However, both static and total temperature rise due to combustion heat release. The static temperature on the upper wall of the combustor is much higher due to multiple reflections and thickening of the boundary layer. The combustion commences much earlier for inlet Mach 2.0 compared to other higher Mach number cases. This could be due to mixing delay. The static temperature rise is noted only when the flow reaches the exit. The static temperature rise is seen only from $\mathrm{X}=940 \mathrm{~mm}$ from the leading 
edge of the combustor inlet as can be seen from Figure 13. The maximum static temperatures attained for the strut configuration of Case 6 (with coordinates $\mathrm{x}_{1} 545.0, \mathrm{y}_{1} 0.0 ; \mathrm{x}_{2}$ 170.0; $\mathrm{y}_{2}$ 15.0) for inlet Mach 2.0, 2.5, and 3.0 are 2730 $\mathrm{K}, 2728 \mathrm{~K}$, and $1631 \mathrm{~K}$, respectively. Thus, combustion is delayed, and efficiency is adversely affected by higher inlet Mach numbers. A similar effect is noted for all the strut configurations studied.

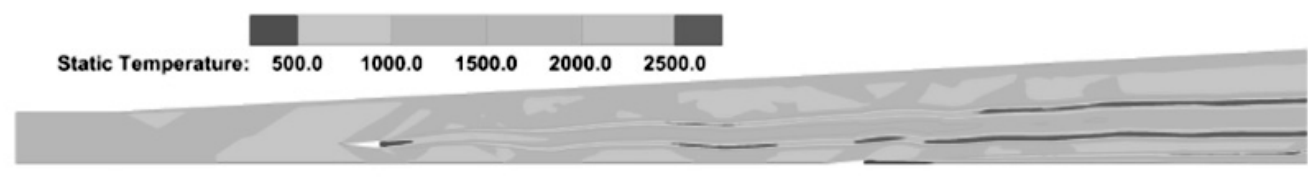

Inlet Mach $=2.0$

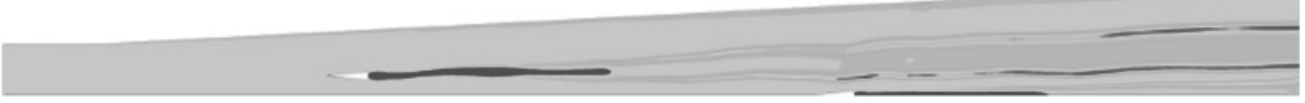

Inlet Mach $=2.5$

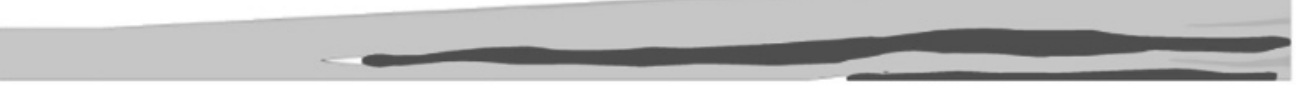

Inlet Mach $=3.0$

Figure 13. Contours of static temperature for the configuration of Case 6 (with coordinates $x_{1} 545.0, y_{1} 0.0$; $\left.\mathrm{x}_{2} 170.0 ; \mathrm{y}_{2} 15.0\right)$.

\section{CONCLUSION}

In a strut-based supersonic combustor, the strut configurations and the operating conditions have a profound influence on the mixing and combustion characteristics. The strut base acts as a flame holder and improves combustion efficiency in the wake region. The fuel residence time is significantly increased with proposed strut configurations. The recirculation region at a subsonic regime shows effective combustion characteristics. The most efficient combustion is noted for the strut configuration of Case 3 (with coordinates $\mathrm{x}_{1} 200.0, \mathrm{y}_{1} 0.0 ; \mathrm{x}_{2} 42.2 ; \mathrm{y}_{2} 30.0$ ). In Case 3 , the secondary struts were placed near the starting of wall divergence, which is upstream of the central strut. The study shows that the efficiency depends heavily on the oblique shock interactions with the main supersonic flow. The proper placement of the struts inside the combustor is important to improve mixing and combustion. The configurations in which the struts are located one above the other and located towards the exit of the combustor have lower combustion efficiency. It is concluded that the combustion efficiency is maximum when two struts are located at the front and one at the back. The interaction of the oblique shock with the main flow is degraded to a larger extent at higher Mach numbers.

\section{ACKNOWLEDGMENT}

All computations were performed on Aziz Supercomputer at King Abdulaziz University's High-Performance Computing Center (http://hpc.kau.edu.sa/). The author would like to acknowledge the computer time and technical support provided by the center.

\section{REFERENCES}

“ANSYS Fluent - CFD Software.” n.d. http://www.ansys.com/Products/Fluids/ANSYS-Fluent.

Bao, Wen, Qingchun Yang, Juntao Chang, Youhai Zong \& Jichao Hu. 2013. "Dynamic Characteristics of Combustion Mode Transitions in a Strut-Based Scramjet Combustor Model." Journal of Propulsion and Power, 29(5): 1244-48.

Baurle, R. \& M. Gruber. 1998. "A Study of Recessed Cavity Flowfields for Supersonic Combustion Applications." In 36th AIAA 
Aerospace Sciences Meeting and Exhibit. Reston, Virigina: American Institute of Aeronautics and Astronautics.

Ben-Yakar, Adela \& Ronald Hanson. 1998. "Cavity Flameholders for Ignition and Flame Stabilization in Scramjets - Review and Experimental Study." In 34th AIAA/ASME/SAE/ASEE Joint Propulsion Conference and Exhibit. Reston, Virigina: American Institute of Aeronautics and Astronautics.

Choi, Jeong-Yeol, Fuhua Ma \& Vigor Yang. 2005. "Combustion Oscillations in a Scramjet Engine Combustor with Transverse Fuel Injection." Proceedings of the Combustion Institute, 30: 2851-58.

Deepu, M, S S Gokhale \& S Jayaraj. 2007. "Numerical Modelling of Scramjet Combustor" 57(4): 367-79.

Gerlinger, Peter, Peter Stoll, Markus Kindler, Fernando Schneider \& Manfred Aigner. 2008. "Numerical Investigation of Mixing and Combustion Enhancement in Supersonic Combustors by Strut Induced Streamwise Vorticity." Aerospace Science and Technology, 12: 159-68.

Grady, Nathan, Robert W. Pitz, Campbell D. Carter, Kuang-Yu Hsu, Chaitanya Godke \& Suresh Menon. 2012. "Supersonic Flow over a Ramped-Wall Cavity Flame Holder with an Upstream Strut.” Journal of Propulsion and Power, 28(5): 982-90.

Ground, Cody R., Fabrizio Vergine, Luca Maddalena \& Valerio Viti. 2014. "Experimental and Numerical Investigation of the Flow Characteristics of a Strut Injector for Scramjets.” In 19th AIAA International Space Planes and Hypersonic Systems and Technologies Conference. Reston, Virginia: American Institute of Aeronautics and Astronautics.

Gruber, M. R., A. S. Nejad, T. H. Chen \& J. C. Dutton. 2000. "Transverse Injection from Circular and Elliptic Nozzles into a Supersonic Crossflow." Journal of Propulsion and Power, 16(3): 449-57.

Hariharan, Vishnu, Ratna Kishore Velamati \& C. Prathap. 2016. "Investigation on Supersonic Combustion of Hydrogen with Variation of Combustor Inlet Conditions." International Journal of Hydrogen Energy, 41(13): 5833-41.

Hönig, R., D. Theisen, R. Fink, R. Lachner, G. Kappler, D. Rist \& P. Andresen. 1996. "Experimental Investigation of a SCRAMJET Model Combustor with Injection through a Swept Ramp Using Laser-Induced Fluorescence with Tunable Excimer Lasers." Symposium (International) on Combustion, 26(2): 2949-56.

Hsu, Kuang-Yu, Campbell Carter, Mark Gruber \& C. J. Tam. 2009. "Mixing Study of Strut Injectors in Supersonic Flows." In 45th AIAA/ASME/SAE/ASEE Joint Propulsion Conference \&amp; Exhibit. Reston, Virigina: American Institute of Aeronautics and Astronautics.

Hu, Jichao, Juntao Chang, Wen Bao, Qingchun Yang \& John Wen. 2014. "Experimental Study of a Flush Wall Scramjet Combustor Equipped with Strut/Wall Fuel Injection.”

Huang, Wei, Hui Qin, ShiBin Luo \& ZhenGuo Wang. 2010. "Research Status of Key Techniques for Shock-Induced Combustion Ramjet (Shcramjet) Engine.” Science in China Series E: Technological Sciences, 53(1): 220-26.

Huang, Wei, ZhenGuo Wang, ShiBin Luo \& Jun Liu. 2011. "Parametric Effects on the Combustion Flow Field of a Typical Strut-Based Scramjet Combustor.” Chinese Science Bulletin, 56(35): 3871-77.

Huang, Wei, Jun Yang \& Li Yan. 2013. "Multi-Objective Design Optimization of the Transverse Gaseous Jet in Supersonic Flows." Acta Astronautica, 93: 13-22.

Huang, Zhi-wei, Guo-qiang He, Fei Qin \& Xiang-geng Wei. 2015. "Large Eddy Simulation of Flame Structure and Combustion Mode in a Hydrogen Fueled Supersonic Combustor." International Journal of Hydrogen Energy, 40(31): 9815-24.

Jeong, Eunju, In-Seuck Jeung, Sean O’Byrne \& A. F. P. Houwing. 2008. “Investigation of Supersonic Combustion with Angled Injection in a Cavity-Based Combustor." Journal of Propulsion and Power, 24(6): 1258-68.

Jianwen, Xing \& Le Jialing. n.d. "Application Of Flamelet Model For The Numerical Simulation of Turbulent Combustion in Scramjet.” Accessed March 27, 2017.

Karagozian, Ann R. 2010. “Transverse Jets and Their Control.” Progress in Energy and Combustion Science, 36: 531-53.

Kumar, Sudarshan, Sudipto Das \& Shekher Sheelam. 2014. "Application of CFD and the Kriging Method for Optimizing the Performance of a Generic Scramjet Combustor." Acta Astronautica 101 (August): 111-19.

Kumaran, K \& V Babu. 2009a. "A Comparison of Numerical Predictions of Supersonic Combustion of Hydrogen Using Different Chemistry Models in a Model Combustor." 47th AIAA Aerospace Sciences Meeting Including the New Horizons Forum and Aerospace Exposition, 8(8): 475-81. 
Kumaran, K. \& Babu, V. 2009b. "Investigation of the Effect of Chemistry Models on the Numerical Predictions of the Supersonic Combustion of Hydrogen." Combustion and Flame, 156: 826-41.

Lee, Kyungjae, Sanghun Kang, Yangji Lee, Bongjun Cha \& Byungil Choi. 2013. "Effects of Fuel Injectors and Cavity Configurations on Supersonic Combustion.” Journal of Propulsion and Power, 29(5): 1052-63.

Mudford, Neil, Peter Mulreany, Jeffrey McGuire, Judith Odam, Russell Boyce \& Allan Paull. 2003. "CFD Calculations for Intake-Injection Shock-Induced-Combustion Scramjet Flight Experiments.” In 12th AIAA International Space Planes and Hypersonic Systems and Technologies. Reston, Virigina: American Institute of Aeronautics and Astronautics.

Oevermann, Michael. 2000. "Numerical Investigation of Turbulent Hydrogen Combustion in a SCRAMJET Using Flamelet Modeling." Aerospace Science and Technology, 4(7): 463-80.

Qin, Fei, Zhi-wei Huang, Guo-qiang He, Shuai Wang, Xiang-geng Wei \& Bing Liu. 2017. "Flame Stabilization Mechanism Study in a Hydrogen-Fueled Model Supersonic Combustor under Different Air Inflow Conditions." International Journal of Hydrogen Energy, 42(33): 21360-70.

Rust, Benjamin, Peter Gerlinger \& Manfred Aigner. 2010. "An Improved Lobed Strut Injector Concept for Supersonic Combustion.” In 46th AIAA/ASME/SAE/ASEE Joint Propulsion Conference \&amp; Exhibit. Reston, Virigina: American Institute of Aeronautics and Astronautics.

Segal, Corin. 2009. The Scramjet Engine : Processes and Characteristics. Cambridge University Press.

Shekarian, Ali Akbar, Sadegh Tabejamaat \& Yashar Shoraka. 2014. "Effects of Incident Shock Wave on Mixing and Flame Holding of Hydrogen in Supersonic Air Flow." International Journal of Hydrogen Energy, 39: 10284-92.

Tomioka, Sadatake, Atsuo Murakami, Kenji Kudo \& Tohru Mitani. 2001. "Combustion Tests of a Staged Supersonic Combustor with a Strut." Journal of Propulsion and Power, 17(2): 293-300.

Vergine, Fabrizio, Luca Maddalena, Victor Miller \& Mirko Gamba. 2012. "Supersonic Combustion and Flame-Holding Characteristics of Pylon Injected Hydrogen in a Mach 2.4 High Enthalpy Flow." In 50th AIAA Aerospace Sciences Meeting Including the New Horizons Forum and Aerospace Exposition. Reston, Virigina: American Institute of Aeronautics and Astronautics.

Zhang, Chenlin, Juntao Chang, Yuanshi Zhang, Youyin Wang \& Wen Bao. 2017. "Flow Field Characteristics Analysis and Combustion Modes Classification for a Strut/Cavity Dual-Mode Combustor Flow Field Characteristics Analysis and Combustion Modes Classification for a Strut/Cavity Dual-Mode Combustor.” Acta Astronautica.

Zhao, Yanhui, Jianhan Liang \& Yuxin Zhao. 2016. "Non-Reacting Flow Visualization of Supersonic Combustor Based on Cavity and Cavity-Strut Flameholder.” Acta Astronautica, 121: 282-91.

Zou, Jian-feng, Yao Zheng \& Ou-zi Liu. 2007. "Simulation of Turbulent Combustion in DLR Scramjet." Journal of Zhejiang University-SCIENCE A 8(7): 1053-58. 